\title{
A Procedural Algorithmic Approach for Functional Structure Construction
}

\author{
Osamah Malik Mohammed \\ Mechanical Engineering Department \\ University of Baghdad \\ Baghdad, Iraq \\ osamadirweesh@hotmail.com
}

\author{
Ahmed Z. M. Shammari \\ Al-Khwarizmi College of Engineering \\ University of Baghdad \\ Baghdad, Iraq \\ drahmed@kecbu.uobaghdad.edu.iq
}

\begin{abstract}
Despite the advances in functional structure modeling, the underlying models are lacking formalism and a consistent basis for successive reasoning. Many researchers have worked on functional structures and in standardizing their vocabulary while some undertook the task of benchmarking the process of creating it, although the effects of functional structure modeling methods and strategies on further stages of conceptual design during concept generation have not been discussed in depth. In the present research, a new procedural algorithmic approach for the functional structure is developed and demonstrated.
\end{abstract}

Keywords-function modeling; functional design; functional structure construction

\section{INTRODUCTION}

The importance and usefulness of functional modeling in engineering design processes has been advocated in numerous engineering design texts [1-9]. The development of functional modeling methods was launched with the verb-noun pair style for describing value analysis functionality. A representation schema was developed in [2] with the consideration that the main usefulness of every product and system comes from its functionality. The transformation of models of energy, material, and information as Input/Output flows was initiated in $[8,10]$ for the functionality description of products and for basic function definitions. The use of basic functions and flow classes was introduced in $[3,11]$. Flow's information was included in a functional basis in [12]. Standardization process for functions and flow vocabulary sets began in 1999 [13], Szykman's vocabulary with different structure and a modified term was developed in 2000 [14]. Authors in [15] built the Reconciled Functional Basis (RFB) in 2002, which has been widely used as a basic library in functional design. The latter is also often called Functional Basis (FB), and because the former is called with the same term, the RFB term will be considered in this paper. There are numerous techniques in functional modeling presented for aiding product's engineering design. In $[16,17]$ a novel Function-Behavior-State (FBS) modeling technique of interconnecting functions with the behavior of function's realization and the Function-Evolution-Process (FEP) were built. Gero's well-known framework of FBS illustrated various domains of conceptual design process as variable classes striving to capture the internal transformations among these three domains [18].
Gero's FBS was extended to situated-Function-BehaviorStructure (sFBS) through the inclusion of dynamic context utilizing environmental interactions [19]. The Behavior-driven Function-Environment-Structure (B-FES) proposed the mapping of function-behavior-physical structure, where the behavior acts as a more detailed high-level functionality [20]. Function-means trees elucidated function's co-dependency that can be fulfilled with means, where it had been hierarchically arranged for building tree structure demonstrating alternative function means for multiple design solutions [21]. After that, the Integrated Definition Method \#0 (IDEF0) introduced a functional modeling framework for identifying elements of an operation performance [22]. Existing functional construction methods may work on reverse engineering in some ways (with existing variations). But they do not work on new designs, i.e. in transferring the designer's vision from the problem of concept generation to the problem of conceptualizing a functional model which may produce a proficient design solution. It is important to develop a structured method for filling this intrinsic gap.

\section{LITERATURE REVIEW OF FUNCTION MODELING}

Authors in [23] investigated and initiated a resolution for representing the functional modeling of relationships for primary and carrier flows using the RFB. Authors in [24] outlined a platform for conceptual design and differentiated modules during product development for planning the product portfolio before conducting embodiment design phase. Authors in [25] presented the Function-Design-Framework (FDF) which supports a hierarchical functional representation for analyzing multi-dimensional complex systems and producing new functional structures. The application of FunctionCAD [26] utilizes FB vocabulary as its main library with a GUI for user-based modeling manipulation and visualization. Authors in [27] updated the previously developed concept generation tool (Form-Follows-Form (FFF) [28]). It allows the designer to use natural language in order to specify the envisioned components and develop the underlying structure of a functional model based on a repository of more than 5500 artifacts. Authors in [29] presented an energy-based functional decomposition for top-down design processes for mechanical systems. Authors in [30] introduced a framework for the integrated object model, functional structure, and architecture 
of a system for exploring the product development process interplaying the physical and software elements in concurrent manner. Authors in [31] introduced a formal representation for function modeling structure graphing controlled by grammar to facilitate reasoning in subsequent stages of conceptual design. Authors in [32] reported a pilot protocol that inspects the way designers build up functional models as they progress and explore solution constructions for new design problems.

Authors in [33] investigated the ability for generating functional structures including three different conditions for construction methods. Authors in [34] presented the Constrained Function-Behavior-Structure (CFBS) knowledge cell for supporting conceptual design with a consistent representation model. A new conceptual design approach for overcoming functional decomposition flaws was suggested in [35]. A controlled experiment for exploring different initial functional structures was conducted in [36]. Authors in [37] investigated the information stored within the component representation of functional structures and applied these structured rules on functional structures. Authors in [38] presented a new methodology for multidisciplinary systems with an automation algorithm for complex automotive cyberphysical systems. Authors in [39] proposed a design method for function combination according to functional redundancy analysis during conceptual design process utilizing the FB vocabulary. Authors in [40] presented a protocol study for developing functional structures for new product designs. Authors in [41] explored the effect of several functional modeling construction methods within various completion levels on the inferencing ability of resulting information. They concluded that the forward functional chaining method is the least favorable irrespective of the completion level, while the performance of backward functional-chaining method is relatively better within all completion levels. The lack of restrictive grammar rules for model inconsistency prevention leads to the lack of structure formalism and adherence to the basic physical laws (conservation and irreversibility laws). The most important gap, is the lack of a proficient structured methodology for functional modeling construction, where all existing chaining methods are highly dependent on the individual designer $[32,42]$. Functional modeling, despite its drawbacks, can help designers understand an existing design and conduct future redesigns or new designs. Functional modeling has often been used as a tool for subsequent phases. Some researchers have worked on developing its basis and construction methods [42].

\section{FUNCTION MODELING STRUCTURE}

A new procedural algorithm solves the mentioned problems efficiently through utilizing human-based processes for the indicated design problem, in which any product can be seen as a human function, through asking its process and for what function it is needed. After importing Customer Requirements (CRs) and correlating manually with their related flows, a black box model is initiated. Then, a human-based process model for the intended product in case of genuine design is built and human efforts are replaced with different sources of energy. Finally, the complete structure is aggregated. The proposed Procedural Rule-based Functional Modeling Structure (PRFS) algorithm is illustrated in Figure 1. The algorithm begins from CRs and finishes with a complete modulized functional structure. Many sets of restrictive grammar rules and facts have been initiated deliberately through noticing previous functional block diagrams. Those rule sets have been utilized in the PRFS algorithm and are categorized into groups which will be elaborated below.

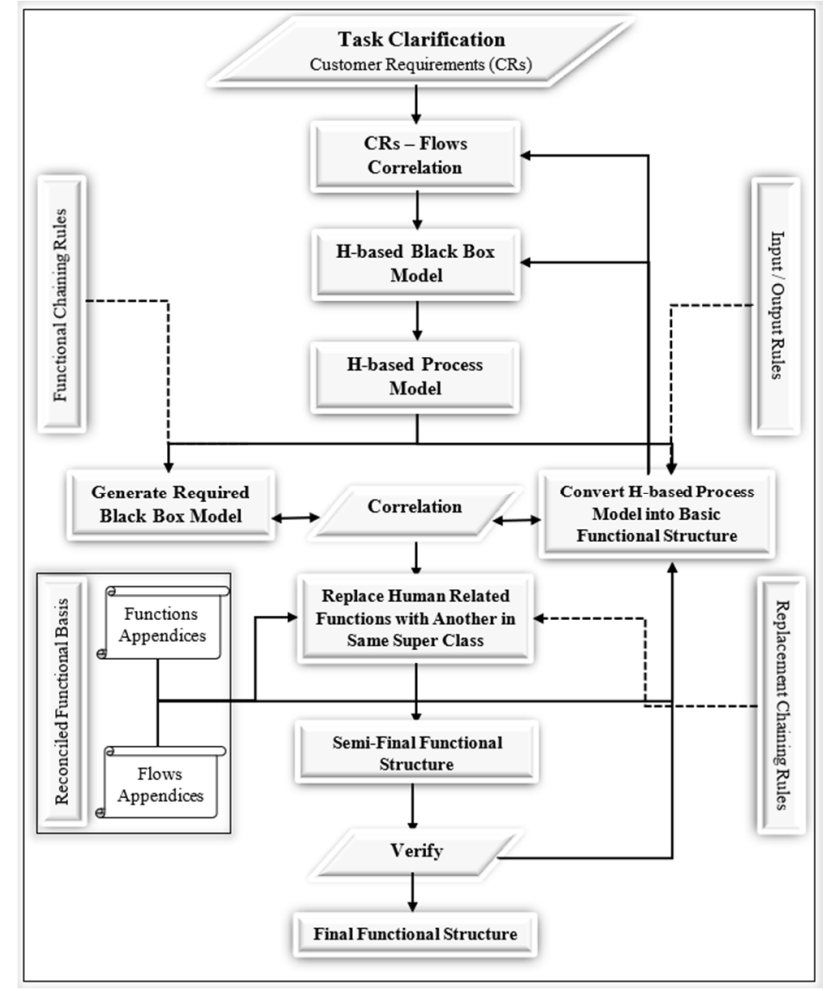

Fig. 1. Developed functional modeling algorithm flowchart.

\section{A. Functional Ontology}

Functional structure chaining identifies model directionality depending on the designer's construction method. There are three chaining methods in the literature (FC, BC, and $\mathrm{NM}$ ) [43].

\section{B. Grammar Rules for Functional Structure}

Grammar rules have been used limitedly in functional structuring and in an unorganized manner. After a deliberated manner on the previous functional block diagrams, four groups for organizing the functional modeling construction have been developed (Input/Output Rules, Functional Chaining Rules, Replacement Chaining Rules, and Meta-Rules), which will be elucidated below.

\section{1) Input / Output Rules}

As illustrated in Table I, input/output governing grammar rules have been initiated for organizing the relations of the functional structure of the box model. Rules 1, 3, and 5 depicted in Figure 2 restrict input/output flow chains along with Facts 1 and 2. Rules 4 and 6 and Fact 3 for restricting Function-Function direct relation and for considering the energy conservation rule are shown in Figure 3. 
TABLE I. INPUT / OUTPUT GRAMMAR RULES

\begin{tabular}{|c|c|c|}
\hline Rule No. & Rules of input / output flows & Figure \\
\hline $\mathbf{1}$ & $\begin{array}{c}\text { IF any } \mathrm{f} \text { type is an input to any } \mathrm{F} \\
\text { THEN it cannot be input to another } \mathrm{F} \text { in the same time }\end{array}$ & 2 \\
\hline $\mathbf{2}$ & $\begin{array}{c}\text { IF f sub-type is } \mathrm{S} \text { in final module } \\
\text { THEN it cannot be tailed with any last output }\end{array}$ & - \\
\hline $\mathbf{3}$ & $\begin{array}{c}\text { IF any } \mathrm{f} \text { is input or output from/to } \mathrm{F} \\
\text { THEN it cannot attach to another } \mathrm{f}\end{array}$ & 2 \\
\hline $\mathbf{4}$ & $\begin{array}{c}\text { IF final output } \mathrm{f} \text { primary class is } \mathrm{M} \text { or } \mathrm{E} \\
\text { THEN it can be with at most one } \mathrm{F}\end{array}$ & 3 \\
\hline $\mathbf{5}$ & $\begin{array}{c}\text { IF } \mathrm{f}_{\mathrm{i}} \text { is an input to } \mathrm{F}_{\mathrm{i}} \\
\text { THEN it cannot be input for same } \mathrm{F}_{\mathrm{i}}\end{array}$ & 2 \\
\hline $\mathbf{6}$ & $\begin{array}{r}\text { IF primary input } \mathrm{f} \text { is primary class } \mathrm{E}_{\mathrm{i}} \text { and/or } \mathrm{F}_{\mathrm{i}} \\
\text { THEN there must be an output } \mathrm{E}_{\mathrm{i}} \text { and/or } \mathrm{F}_{\mathrm{i}}\end{array}$ & 3 \\
\hline Fact $\mathbf{1}$ & Any $\mathrm{F}_{\mathrm{i}}$ cannot be direct input or output to/from another $\mathrm{F}_{\mathrm{i}}$ & 2 \\
\hline Fact $\mathbf{2}$ & f can have at most one carrier & 2 \\
\hline Fact $\mathbf{3}$ & Any $\mathrm{F}_{\mathrm{i}}$ cannot be an input or output & 3 \\
\hline
\end{tabular}
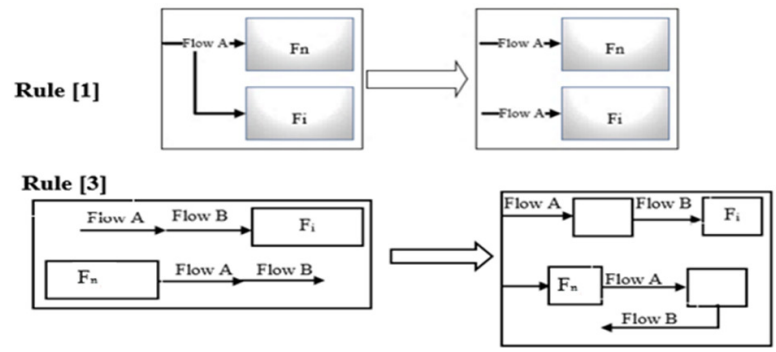

Rule [5]

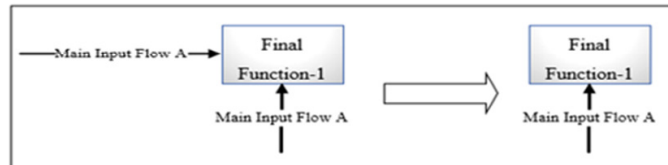

Fact [1]

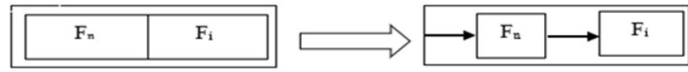

Fact [2]

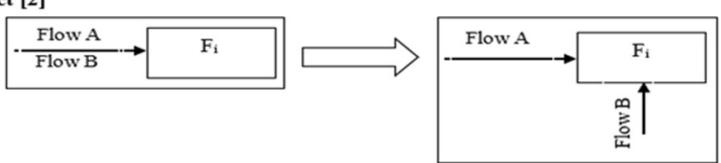

Fig. 2. Input/output rules for the developed functional structure modelingRules 1, 3, and 5 and Facts 1 and 2.

\section{2) Functional Chaining Rules}

Functional chaining rules govern the constructing internal relations of functional chains (Table II, Figure 4). Rule 7 supports the primary class Branch Function, which must contain more than the output flow to be reasoned. Rule 8 of using primary class Convert Function obligates the changing of the energy type. Rule 9 represents the energy loss after pruning Rule 8. Rules 10-12 obligate input flow type $f_{i}$ as the same output flow type $\mathrm{f}_{\mathrm{i}}$.

\section{3) Replacement Chaining Rules}

These set of rules are initiated for converting the basic functional structure, and are generated after the building of the Human-Centric Process Model (HPM), as illustrated in Table III. Rule 14 replaces human GUIDE functions into similar ones through changing the Flow type $f_{i}$ from primary class Energy (except HE). These Rules are shown in Table III and Figure 5. Rules 15-16 are introduced for the TRANSFER (conduct, convey) and the TRANSPORT (advance, lift, move) functions which belong to a secondary class of the CHANNEL primary class. They can't change the function, but do change the flow in and flow out of it. In Rule 17, the secondary class MIX is for changing the previous function and changing in-out flows for transforming manual processes (add, blend, coalesce, combine, pack) into tooled, motorized or automated, depending on CRs and designer's intent and objective.
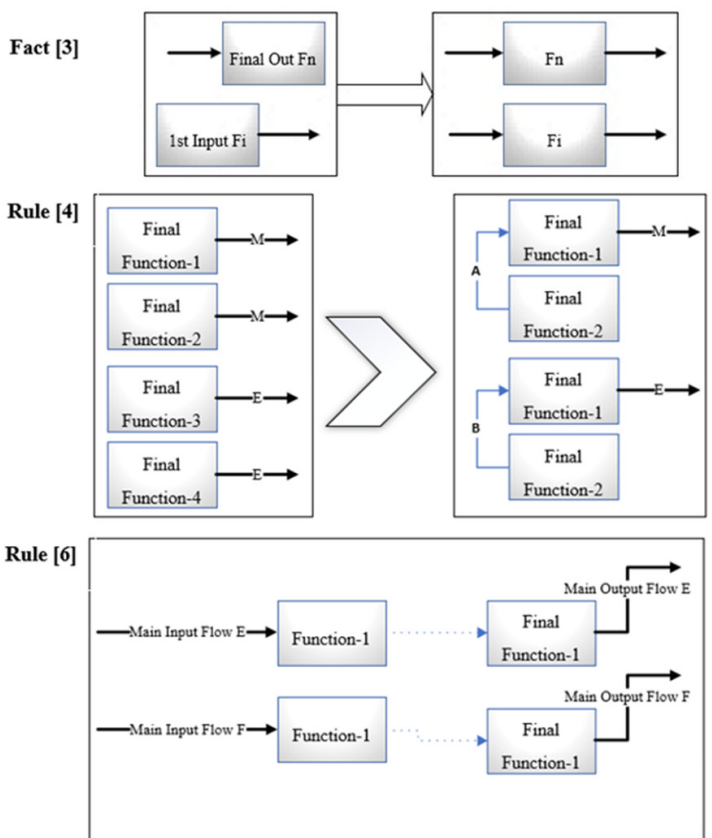

Fig. 3. Input/output rules for the developed functional structure modeling - Rules 4 and 6 and Fact 3.

TABLE II. FUNCTIONAL CHAINING RULES FOR DEVELOPED FUNCTIONAL STRUCTURE CONSTRUCTION

\begin{tabular}{|c|c|c|}
\hline Rule No. & Functional Chaining Rules & Figure \\
\hline $\mathbf{7}$ & $\begin{array}{c}\text { IF Function } \mathrm{F}_{\mathrm{i}} \text { primary class type is BRANCH } \\
\text { THEN it must have }>1 \text { output flow to another } \mathrm{F}_{\mathrm{i}+1} \\
\text { AND one input flow }\end{array}$ & 4 \\
$\mathbf{8}$ & $\begin{array}{c}\text { IF Function } \mathrm{F}_{\mathrm{i}} \text { primary class type is CONVERT } \\
\text { AND Flow } \mathrm{f}_{\mathrm{i}} \text { is a secondary class type of Energy } \\
\text { THEN Output can be any secondary class type of Energy } \\
\text { except } \mathrm{f}_{\mathrm{i}}\end{array}$ & 4 \\
\hline $\mathbf{9}$ & $\begin{array}{c}\text { IF Function } \mathrm{F}_{\mathrm{i}} \text { primary class type is CONVERT } \\
\text { AND Flow } \mathrm{f}_{\mathrm{i}} \text { is a secondary class type of Energy } \\
\text { THEN Output must contain another loss flow } \mathrm{f}_{\mathrm{i}}\end{array}$ & 4 \\
\hline $\mathbf{1 0}$ & $\begin{array}{c}\text { IF any input Flow } \mathrm{f}_{\mathrm{i}} \text { to secondary class function TRANSFER } \\
\text { THEN output Flow must be the same } \mathrm{f}_{\mathrm{i}}\end{array}$ & 4 \\
\hline $\mathbf{1 1}$ & $\begin{array}{r}\text { IF any input Flow } \mathrm{f}_{\mathrm{i}} \text { to secondary class function GUIDE } \\
\text { THEN output Flow must be the same } \mathrm{f}_{\mathrm{i}}\end{array}$ & 4 \\
\hline $\mathbf{1 2}$ & $\begin{array}{c}\text { IF any input Flow } \mathrm{f}_{\mathrm{i}} \text { to primary class function CHANNEL } \\
\text { THEN output Flow must be the same } \mathrm{f}_{\mathrm{i}}\end{array}$ & 4 \\
\hline
\end{tabular}

\section{4) Meta-Rules for Functional Structure}

For restricting the previously initiated grammar rules, a set of meta rules is introduced for organizing the replacement ruleset firing as illustrated in Table IV. 


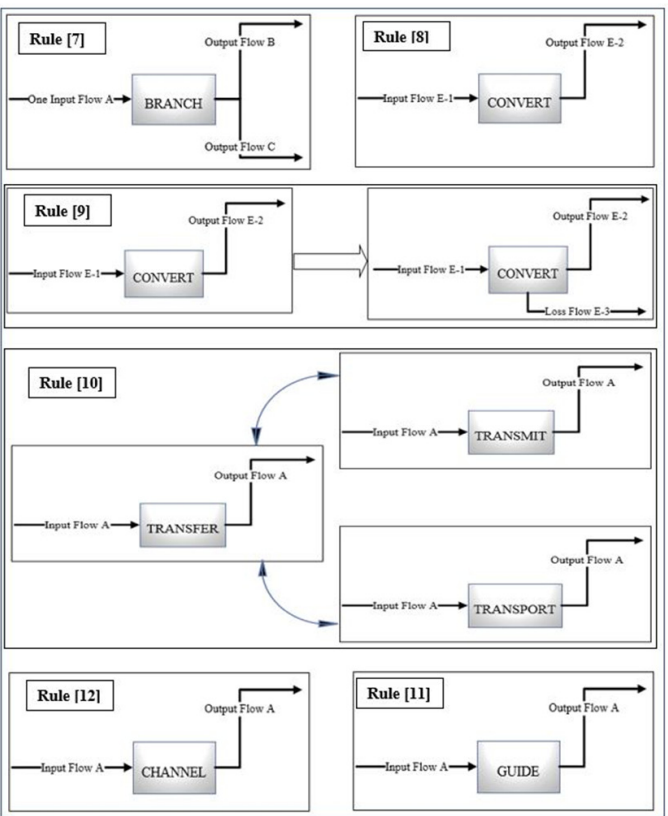

Fig. 4. Functional chaining rules for the developed functional structure construction - Rules 7-12.

TABLE III. REPLACEMENT CHAINING RULES

\begin{tabular}{|c|c|}
\hline Rule No. & Replacement chaining rules \\
\hline 13 & $\begin{array}{c}\text { IF any Flow }\left[\mathrm{f}_{\mathrm{i}}\right] \text { type is, } \mathrm{HE} \text { as input to } \mathrm{F} \\
\text { AND F sub-type is Second Class IMPORT } \\
\text { THEN change } \mathrm{f} \text { type/sub-type to any other f First class E }\end{array}$ \\
\hline 14 & $\begin{array}{c}\text { IF any Flow }\left[\mathrm{f}_{\mathrm{i}}\right] \text { type is, } \mathrm{HE} \text { as input to } \mathrm{F} \\
\text { AND F sub-type is Second Class GUIDE } \\
\text { THEN change } \mathrm{f} \text { type/sub-type to any other f First class E }\end{array}$ \\
\hline 15 & $\begin{array}{c}\text { IF any Flow }\left[\mathrm{f}_{\mathrm{i}}\right] \text { type is, } \mathrm{HE} \text { as input to } \mathrm{F} \\
\text { AND F sub-type is Second Class TRANSFER } \\
\text { THEN change } \mathrm{f} \text { type/sub-type to any other f First class E }\end{array}$ \\
\hline 16 & $\begin{array}{c}\text { IF any Flow }\left[\mathrm{f}_{\mathrm{i}}\right] \text { type is, } \mathrm{HE} \text { as input to } \mathrm{F} \\
\text { AND F sub-type is Second Class TRANSPORT } \\
\text { THEN change } \mathrm{f} \text { type/sub-type to any other f First class E }\end{array}$ \\
\hline 17 & $\begin{array}{c}\text { IF any Flow }\left[\mathrm{f}_{\mathrm{i}}\right] \text { type is, HE as input to } \mathrm{F}_{\mathrm{i}} \\
\text { AND F sub-type is Secondary Class MIX } \\
\text { THEN change } \mathrm{f} \text { type/sub-type to any other } \mathrm{f} \text { First class E }\end{array}$ \\
\hline
\end{tabular}

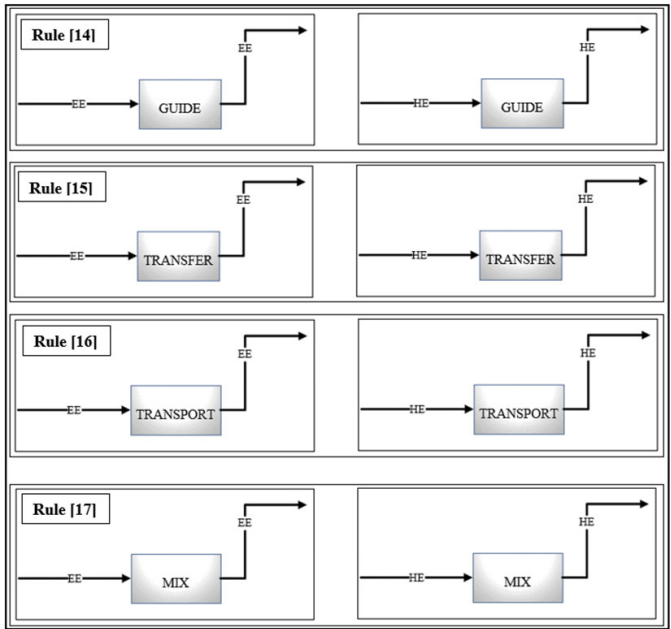

Fig. 5. Replacement chaining rules for the developed functional structure construction - Rules 14-17.

\section{TABLE IV. META-RULES}

\begin{tabular}{|c|c|}
\hline Rule No. & Modules conversion rules \\
\hline $\mathbf{1 8}$ & IF Rule 4 is fired with Fact 2 THEN fire Rule 6 \\
\hline $\mathbf{1 9}$ & IF Rule 13 is fired with Facts 1-3 THEN fire Rule 6 \\
\hline $\mathbf{2 0}$ & IF Rule 8 is fired THEN fire Rule 9 \\
\hline $\mathbf{2 1}$ & IF Rule 17 is fired THEN fire Rule 9 \\
\hline
\end{tabular}

\section{THE DEVELOPED PRFS MODULE}

In this section, the Procedural Rule-based Functional Modeling Structure (PRFS) model of the functional structure algorithm is introduced and elaborated.

Step 1 initializes the CRs. This was conducted by a questionnaire survey and direct interviews. CRs are categorized as Constraints, Main Flows, and Specifications. Constraints are utilized in the Evaluation phase. The Main Flows are used for generating the human-based black box model and the required black box model. In Step 2, a Human-Centric Model (HCM) will be constructed and then a Basic Functional Structure (BFS) model will be developed depending on the RFS, by simply transforming the process model into FB vocabulary. Step 3 correlates the main flows of the required black box model with the basic functional structure for these two cases:

- Divergent Flow: if there is a divergent flow that has not been found in the basic functional structure, then another sub-function is added and its output flow convergence is inspected. If the case remains the same, another subfunction will be added.

- Convergent Flow: if the main input/output flows are convergent with the main input/output flows of the basic functional structure, then the internal sub-function chain $/ \mathrm{s}$ is inspected for decreasing human intervention.

In Step 4, the final functional model depending on the previously elicited rules is developed. The process can be conducted as:

- Insertion: the flows and functions of unsatisfied CRs of the HCM built in Step 2 are inserted in the final basic functional structure.

- Elicitation: eliciting core functionality modules according to the HPM through generating separated modules for each sub-process of manual operation of the product to be designed.

- Aggregation: aggregating core functionality with related interactions through replacing human energy and materials with other kinds of energy and materials upon requirement.

- Outline: all inputs and outputs should be included in the final required black box model.

In Step 5, the final functional structure according to the main flow correspondence and module sub-function chains is verified and matched with the process model and the basic functional structure of Step 2. If the final functional structure aspects have not met, Step 3 is repeated. Else, the design structure is finalized. The developed rule-based functional structure model algorithm is elaborated with correlating rules at each step as shown in Figure 6. 


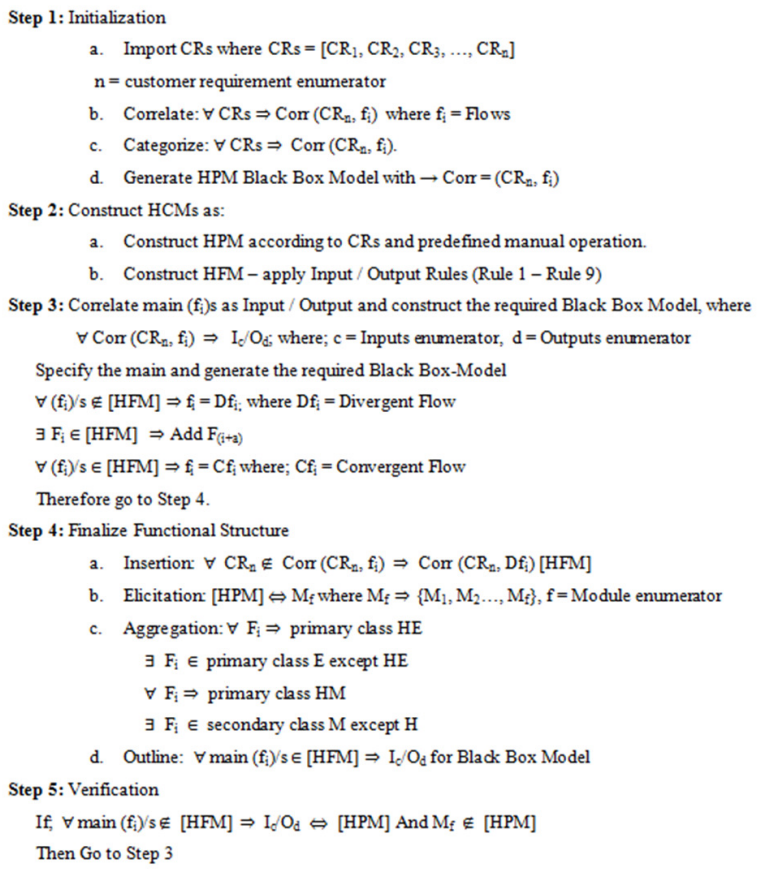

Fig. 6. The rule-based functional structure model algorithm pseudocode.

\section{A. Case Study 1 - Box Labeling Device}

The functional decomposition process begins from the overall function which is the same as in the black-box model modules and sub-modules as depicted in Figure 7. For initializing such a functional structure according to the PRFS algorithm, firstly, the HPM should be built depending on the manual processes of the intended product. During the design of the box-labeling device, it is supposed that the workers have a physical disability and this device can help them overcome it. Irrespectively, there are multiple modeling structures for functional diagrams, all the methods start with building a black-box model and translating its flows to build the subfunction structural chains. Generally, the black-box model of the current case study has been built as a conversion of CRs into related flows, as shown in Figure 8.

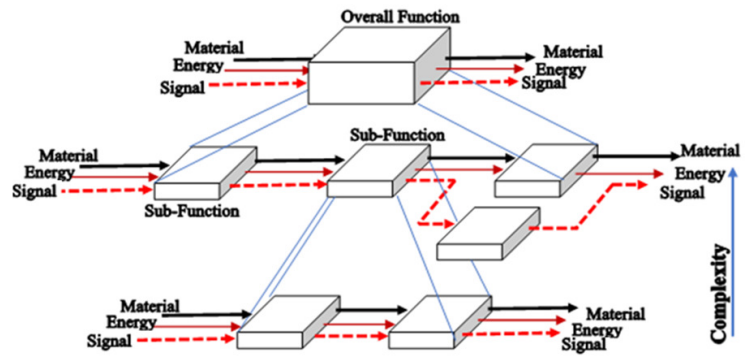

Fig. 7. Functional decomposition process.

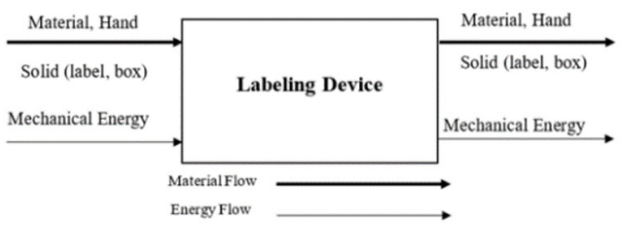

Fig. 8. Black-box model of the labeling device.

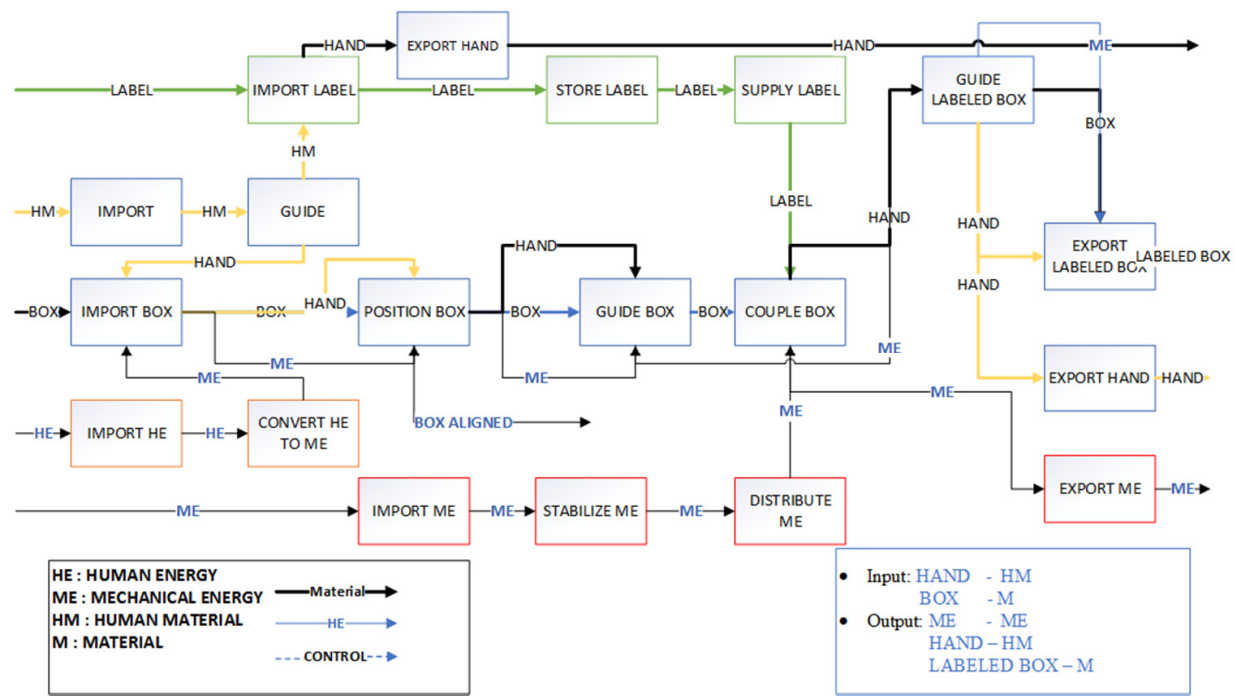

Fig. 9. Main functional structure for box-labeling device.

\section{- Original Functional Structure: Box Labeling Device}

The functional structure is constructed according to forward chaining of the labeling process, and converting its vocabulary utilizing Hirtz's RFB. The built functional structure is depicted in Figure 9. The functional structure has been divided into several chains randomly (flow chains A-E) so as to be prepared for concept generation algorithm (Figure 10). Flow chain A represents Human Material and its flow inside the product with yellow color interacts with the labeling process (green) in the IMPORT function. Human Energy flow is represented with grey color. It is to be converted to Mechanical Energy and interacts with the IMPORT function of the box component. The Mechanical Energy (ME) has its own flow that interacts with the Material Flow of the box component in the COUPLE function. 


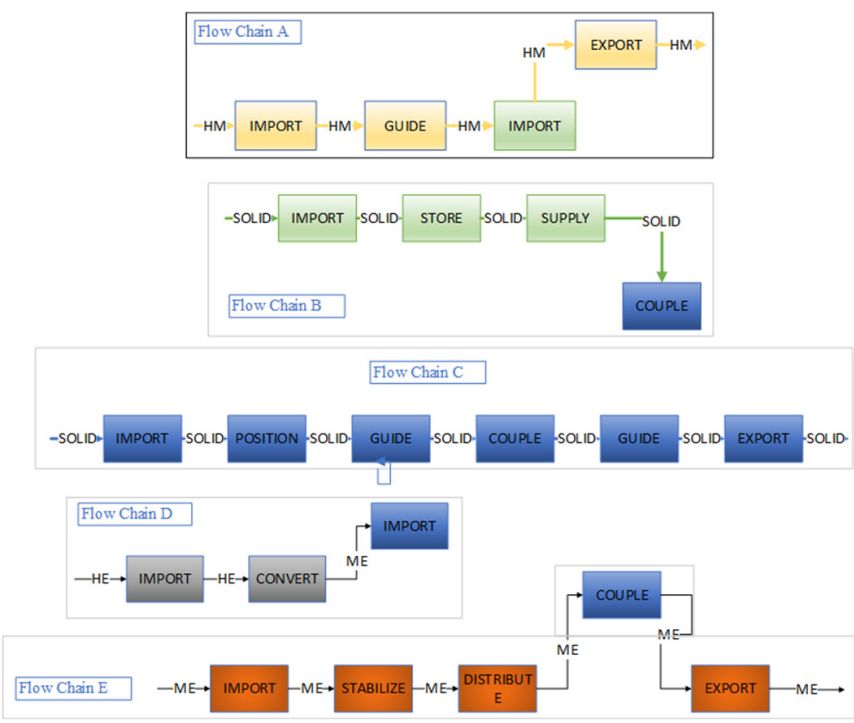

Fig. 10. The decomposed conceptual model as single non-branching flow chains.

Table $\mathrm{V}$ shows the assessed function types and related flows with their occurrences and the sub-functions for clarifying the functional structure components. It can be seen that the inconsistent manner in converting CRs in their related flows was neglected, which affects directly the sub functional chaining procedure which is also constructed vaguely depending upon forward chaining methods.

TABLE V. FLOW-FUNCTION-FLOW PAIRS OF THE TRANSMISSION MECHANISM

\begin{tabular}{|c|c|c|c|c|}
\hline Flow & Function & Flow & Occurrences & Sub-function \\
\hline EE & IMPORT & EE & 1 & IMPORT EE \\
\hline EE & CONVERT & RE & 1 & CONVERT EE to RE \\
\hline RE & TRANSMIT & RE & 2 & TRANSMIT RE \\
\hline RE & CONVERT & TE & 2 & IMPORT SOLID \\
\hline TE & TRANSMIT & TE & 1 & TRANSMIT TE \\
\hline TE & CONVERT & RE & 1 & CONVERT TE to RE \\
\hline TE & EXPORT & TE & 1 & EXPORT TE \\
\hline & 4 types & 3 types & 9 & 7 subfunctions \\
\hline
\end{tabular}

\section{B. Case Study 2 - Transmission Mechanism}

In industrial loading platforms, transmission mechanisms represent a critical key for multiple repetitive usage at many divisions. The current transmission mechanism has been known for verifying the capability of the proposed approach to deal with such design problems and comparing the results of redesigning a real product. A design team has been employed to redesign a transmission mechanism that has been used for loading and unloading materials in an industrial platform. The existing device couldn't meet the requirements of field application due to the short transmission distance. The redesign is required to be durable and usable for a long time.

\section{- Transmission Mechanism: Functional Structure}

The functional structure has been built with reverse engineering. Backward Chaining method was used in building a single branch structure utilizing the vocabulary of Reconciled FB. The main suggested input flow is Electrical Energy (EE) and the final output is Translational Energy (TE), while the rest of sub functions are depicted in Table VI. The functional structure has been built utilizing 9 sub functions, 3 flow types, and 4 function types. The functional structure has been divided into two modules for facilitating the reasoning process in the concept generation system. The Main Functional Structure and its decomposed modules (Upper Subassembly Module - Lower Subassembly Module) are illustrated in Figure 11. Module-A illustrates the conversion of EE into translational energy, while module-B depicts the transmitting TE through many sub functions of conversion so as to be finally exported. This will give the designer a potential to understand the system design and its functionality and forecast future improvements through changing only the desired subfunctions.

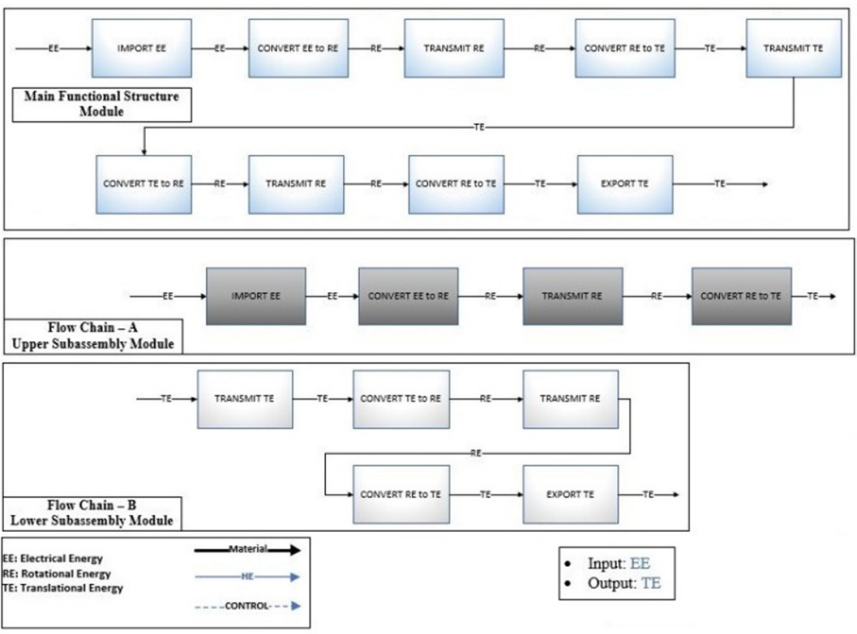

Fig. 11. Functional structure of the transmission mechanism with decomposed modules.

TABLE VI. FLOW-FUNCTION-FLOW PAIRS OF TRANSMISSION MECHANISM

\begin{tabular}{|c|c|c|c|c|}
\hline Flow & Function & Flow & Occurrences & Sub-function \\
\hline HM & IMPORT & HM & 2 & IMPORT HM \\
\hline HM & GUIDE & HM & 1 & GUIDE HM \\
\hline HM & EXPORT & HM & 2 & EXPORT HM \\
\hline SOLID & IMPORT & SOLID & 2 & IMPORT SOLID \\
\hline SOLID & STORE & SOLID & 1 & TRANSMIT TE \\
\hline SOLID & SUPPLY & SOLID & 1 & SUPPLY SOLID \\
\hline SOLID & COUPLE & SOLID & 1 & COUPLE SOLID \\
\hline SOLID & POSITION & SOLID & 1 & POSITION SOLID \\
\hline SOLID & GUIDE & SOLID & 2 & GUIDE SOLID \\
\hline SOLID & EXPORT & SOLID & 1 & EXPORT SOLID \\
\hline HE & IMPORT & HE & 1 & IMPORT HE \\
\hline HE & CONVERT & ME & 1 & CONVERT HE to ME \\
\hline ME & STABILIZE & ME & 1 & STABILIZE ME \\
\hline ME & DISTRIBUTE & ME & 1 & DISTRIBUTE ME \\
\hline ME & COUPLE & ME & 1 & COUPLE ME \\
\hline ME & EXPORT & ME & 1 & EXPORT ME \\
\hline & 10 Types & 4 Types & 20 & 16 Types \\
\hline
\end{tabular}

\section{DISCUSSION AND ANALYSIS OF EXPERIMENTS 1 AND 2}

There are three main parts concerned with those simple cases, functional structure construction, concept generation, and solution selection. Functional structure is constructed depending on RFB vocabulary without specifying a 
construction method or its modules, only the transmission mechanism case is decomposed depending on the PRFS algorithm, while the labeling device structure is fixated for verifying the concept generator.

\section{CASE STUdY 3 - NEW DESIGN}

In healthcare sector, pharmaceutical machines and devices represent a competing industry, which is growing towards automation. Mostly, mini lab tasks are conducted manually, for many reasons. Mixers and blenders are used informally for specific tasks and are not specialized for the medical sector in general and the pharmaceutical field in particular. Our goal is to design a new multifunction-mixer/blender and grinder for laboratory and pharmaceutical dermatological and other related chemical preparations. Ointment, cream, oils and/or powders can be grinded and/or mixed and blended in specific amounts according to prespecified requirements and conditions. Designing a product for dermatological and related chemical preparations that can be used in laboratories and pharmacies instead of the current error-prone manual methods can save effort, cost, time, and augment process efficiency.

\section{A. Customer Requirements}

CRs are collected and rated through direct interviews and a questionnaire survey at three levels. The first level identifies the manual process that needs to be mechanized, the second level specifies the basic characteristics and requirements for the intended product design, at the third level, and according to the questionnaire, the pre-specified CRs are rated according to their importance as illustrated in Figure 12. The questionnaire depicted in [15] was introduced to 27 expert pharmacists (18 from Baghdad and 9 from Wasit governorates) under the supervision of SIP (Syndicate of Iraqi Pharmacists). The results of customer importance ratings were normalized for brevity reasons. Customer needs and their related specifications are categorized into two categories (Flows and Constraints), where, Flows $\left(f_{i}\right)$ are further subcategorized into main and internal flows. The results of the revised specifications and their importance ratings with related flows are shown in Table VII.

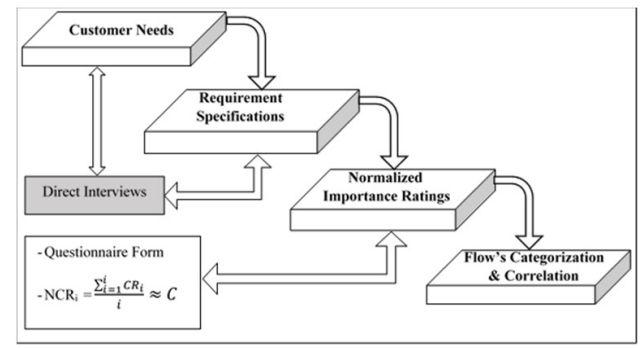

Fig. 12. Customer requirements elicitation process.

\section{B. Functional Model Structure: New Design}

The functional structure model and its decomposed modules and submodules are constructed starting from building the HPM for the current manual procedure of product design.

\section{1) Generate Black Box Model: New Design}

A black box model is created after completing a list of flows for each customer need. According to CRs and specifications, the input/output flows are established easily, and each customer need is identified by one or more input and/or output flows for the whole product. In Figure 13, an initial black box model is established for the manual processing of a typical preparation process. It can be seen that the mixing process is executed separately with complete human intervention and the grinding process requires human interaction (hand), separately from the mixing process. According to the required specifications, their related flows $\left(f_{i}\right)$, and the black box model of manual process, a new black box model is developed as illustrated in Figure 14. The input/ output grammar rule set is utilized along with a replacement rule set, where human energy is eliminated and replaced by EE which will have a big effect on the subsequent functional chaining decomposition processes. In the same time, the two black boxes in Figure 13 are merged to one integrated black box model as depicted in Figure 14.

TABLE VII. REQUIRED SPECIFICATIONS FOR THE PRODUCT

\begin{tabular}{|c|c|c|c|}
\hline Customer Need & $\begin{array}{c}\text { Specified } \\
\text { requirements }\end{array}$ & $\begin{array}{c}\text { Normalized } \\
\text { importance }\end{array}$ & Related flows \\
\hline Particle size & $65 \mathrm{mcg}-210 \mathrm{mcg}$ & 5 & $\mathrm{M}$ \\
\hline $\begin{array}{c}\text { Grinded / blended } \\
\text { materials }\end{array}$ & $\begin{array}{c}\text { Powder, ointment, } \\
\text { cream and/or oils }\end{array}$ & 5 & Black-box \\
\hline Capacity & $20 \mathrm{~g}-150 \mathrm{~g}$ & 5 & Store \\
\hline Electrical consumption & $0-350 \mathrm{~W}$ & 1 & EE \\
\hline Preparation time & $0-20$ minutes & 4 & Constraint \\
\hline Easier mounting & - & 5 & HE \\
\hline Provide attachments & - & 2 & Constraint \\
\hline Suitable size & $20-40 \mathrm{~cm}$ & & Constraint \\
\hline Shape for corners & Rounded & 1 & Constraint \\
\hline Easy to operate & Manual - semi- & 3 & HE, on/off \\
\hline Well balanced & - & 3 & Weight \\
\hline More power & - & & EE \\
\hline Provide cord & - & 5 & EE \\
\hline Wet/dry materials & Non-sticky & 5 & Constraint \\
\hline Easy storage & - & 4 & Material, hand \\
\hline Easy to empty & - & 2 & Constraint \\
\hline Light weight & $<5 \mathrm{Kg}$ & 5 & Constraint \\
\hline Cost & $<400 \$$ & Housing \\
\hline Stability & - & 2 & \\
\hline & & & 5 \\
\hline
\end{tabular}

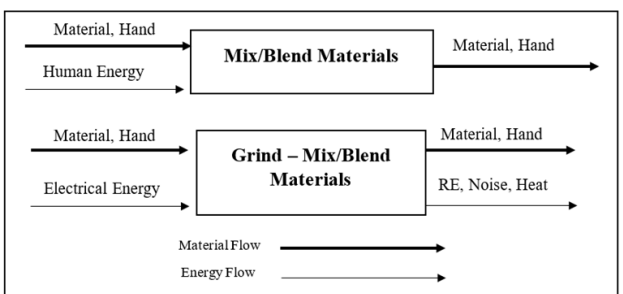

Fig. 13. The HPM-based black box model for a typical preparation process.

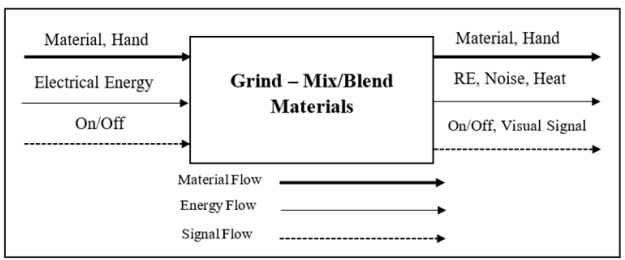

Fig. 14. The black box model for the pharmaceutical grindermixer/blender. 


\section{2) Building Functional Chains: New Design}

As an example, in Table VI, the customer need no. 10 with its related specifications (manual, semi-automated) and related flow is HE, On/Off, which is its Control Signal (CS) that has been submitted as the main input to the new developed black box model in Figure 14. At this stage, the Step 1 of the PRFS algorithm is completed. After generating the black box model which includes the main input/output flows, in Step 2, a HPM is constructed by developing the process model for the operations that are needed to be transformed for the designed product and then a basic functional structure model (HFM) depending on RFB is developed. The functional structure model in this step is the basic model for the previously developed process model, by simple transformation of the process model into RFB vocabulary. "Become the flow" is the basic principle followed in generating functional chains through considering each operation from start to the final product (transferring to another function or transforming to another flow) and expressing it in verb-object form as subfunctions. The manual process is modeled according to the RFB in Figure 15. A typical manual procedure can be summarized in the following steps:

1. Prepare the required materials.

2. Scale each material as specified for mixing.

3. Inspect visually the particle size of the powder. If the particle size is more than required, then go to step 4 , else go to step 5 .

4. Grind the powder to the accepted particle size.

5. Transfer the powder and the other materials to a smooth surface.

The materials are mixed/blended until they form a homogenous mixture. According to [15], the functional manual procedure (HPM model) is transformed to a basic functional model depending upon RFB vocabulary (Figure 16). After applying the functional chaining rule set, the block CONVERT $\mathrm{EE}$ to $\mathrm{RE}$ is followed with generating ThE (Thermal Energy) and $\mathrm{AE}$ (Acoustic Energy) in order to meet the conservational laws of physics and adjust correspondent manual functions according to the RFB vocabulary. A summary of the generated subfunctions is elucidated in Table VIII. The PROCESS function is used to indicate scaling processes according to their correspondents in RFB vocabulary, while CHANGE is used for the filtration process and EXTRACT can be used for the same purpose at secondary classes. The last function is used to widen the search process. Mostly, using the primary class will produce more general solution space, and the secondary class contains more than $80 \%$ of the solution space as depicted in Table VIII.

TABLE VIII. OCCURRENCES OF INPUT/OUTPUT [ $\mathrm{f}_{\mathrm{i}}$ ] AND ITS RELATED $\left[\mathrm{F}_{\mathrm{i}}\right]$

\begin{tabular}{|c|c|c|c|c|c|c|c|}
\hline$\left[\mathbf{f}_{\mathbf{i}}\right]$ & $\mathbf{O c c}_{\mathbf{i}}$ & {$\left[\mathbf{f}_{\mathbf{i}}\right]$} & $\mathbf{O c c}_{\mathbf{i}}$ & {$\left[\mathbf{F}_{\mathbf{i}}\right]$} & $\mathbf{O c c}_{\mathbf{i}}$ & {$\left[\mathbf{F}_{\mathbf{i}}\right]$} & Occ \\
\hline $\begin{array}{c}\text { PARTICULA } \\
\text { TE }\end{array}$ & 12 & HM & 3 & IMPORT & 5 & TRANSMIT & 1 \\
\hline MATERIAL & 8 & CS & 1 & PROCESS & 2 & CONVERT & 3 \\
\hline MIXTURE & 5 & HE & 2 & CHANGE & 1 & GUIDE & 1 \\
\hline RE & 4 & EE & 7 & STORE & 3 & MIX & 1 \\
\hline ME & 3 & & & EXPORT & 3 & TRANSFER & 1 \\
\hline ThE & 2 & & & TRANSPORT & 3 & & \\
\hline AE & 2 & & & ACTUATE & 1 & & \\
\hline
\end{tabular}

At this point, Step 3 of the PRFS algorithm is executed and the divergent flows are inspected. If a flow in the initial black box model was missed from the functional structure model, then it must be added with its related sub-function and other decomposed functions and flows. When all input and output flows converge, then we may move to Step 4 of the algorithm. This step is the most important, and includes four sub steps:

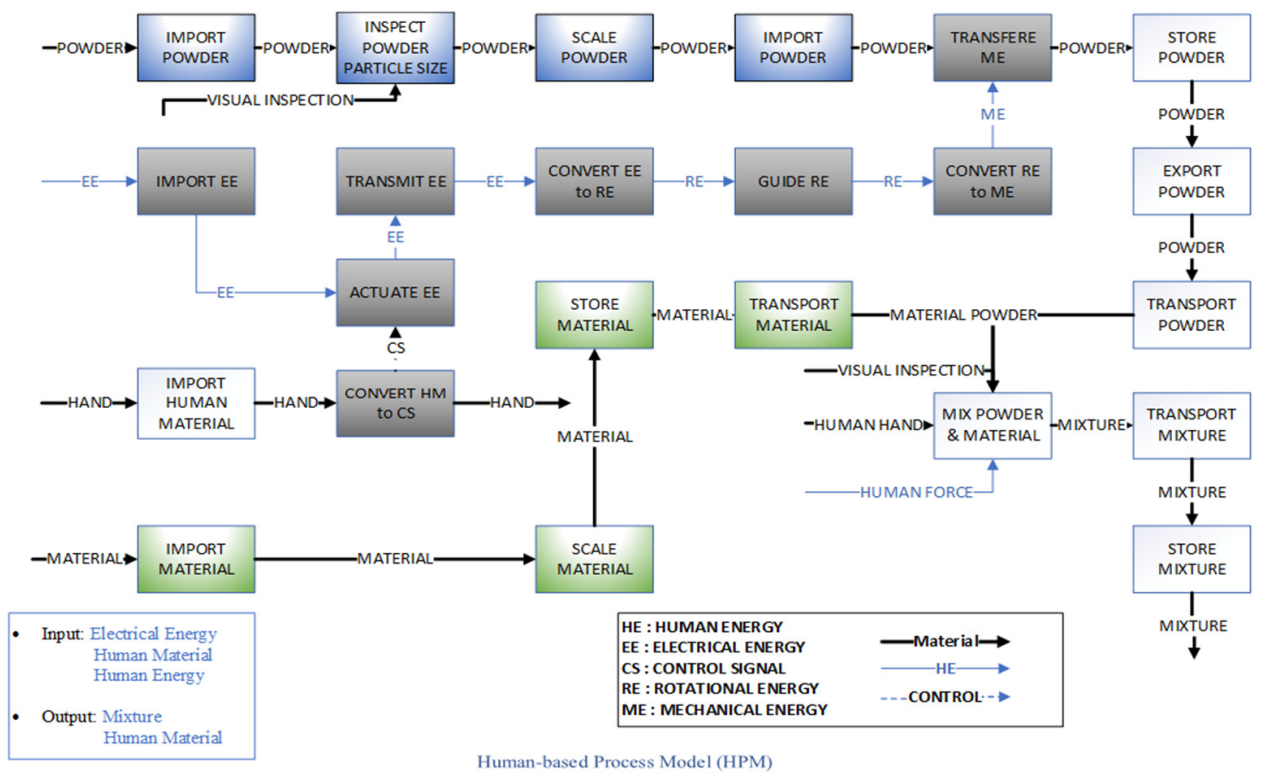

Fig. 15. Functional manual procedure for a typical dermatological preparation. 


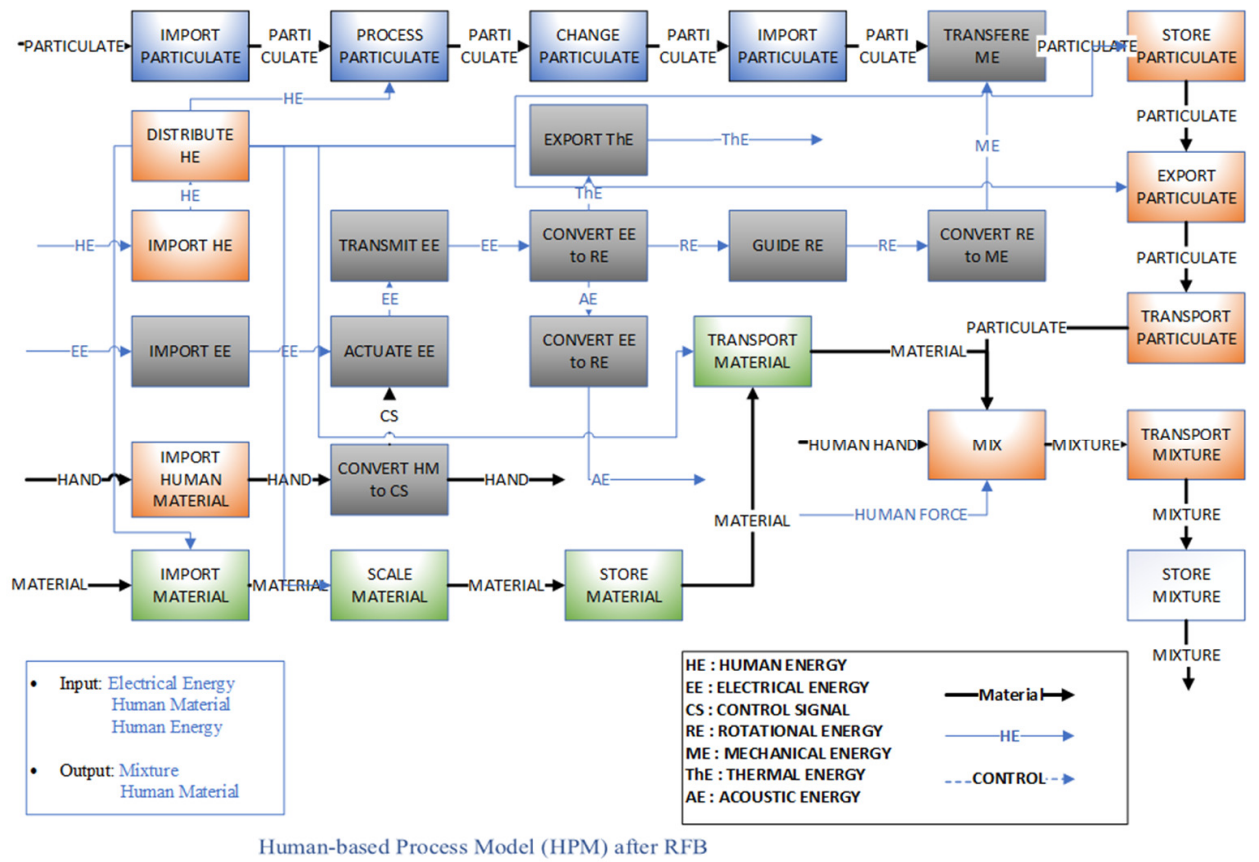

Fig. 16. FS-model based-RFB of HPM for a typical dermatological preparation.

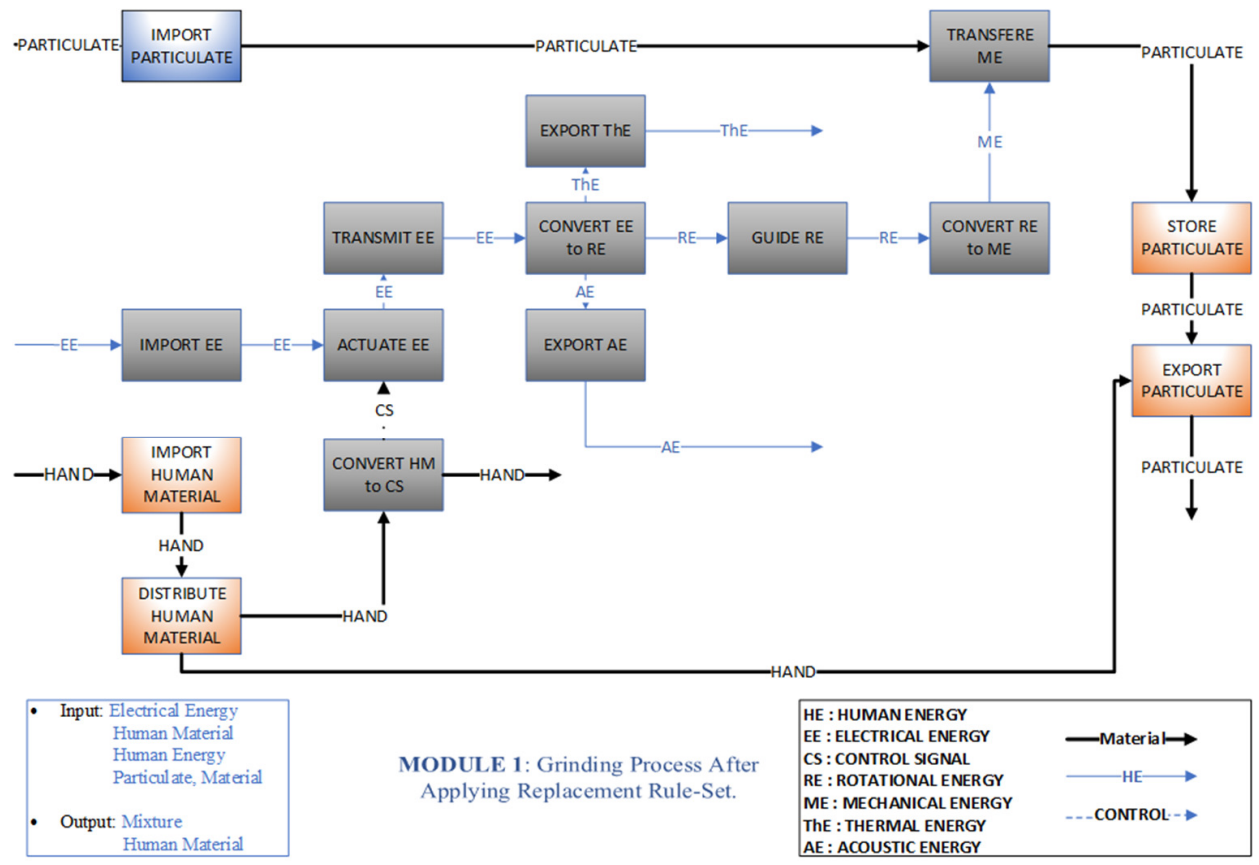

Fig. 17. Module-1 grinding process after applying PRFS rule sets.

a) Insertion

If there was an internal chaining flow missed from the functional structure in Figure 16, then it must be modified. For brevity reasons, modifications are illustrated in the final functional structure in Figure 21.

\section{b) Elicitation}

According to the HPM structure in Figure 15, core functionality modules are elicited through generating separated modules for each sub-process of the manual operation of the product that should be designed.

- Blue blocks refer to the separated manual process of importing powder, scaling, and transferring it to the grinding process.

- Gray blocks refer to the mechanized grinding process from importing electricity and sharing "TRANSFERE" function with blue blocks. 
- Green blocks refer to importing other materials and repeating the previous actions from transferring to mixing.

- White blocks refer to shared blocks among several modules.

After constructing the functional structure in Figure 16, the HPM structure is developed and multiple subfunctions and flows are added to meet the CRs. Orange blocks refer to human interaction with the shared blocks and other modules. The first module (Figure 17), is decomposed into three shared submodules as depicted in Figure 18. Dark blue "TRANSFERE ME" refers to its sharing with a blue module, while dark green "EXPORT PARTICULATE" refers to its sharing with the green module of human interaction. Shared subfunctions work like a strong connection at later phases of concept generation.
Shared subfunctions $\left[\mathrm{f}_{\mathrm{i}}-\mathrm{F}_{\mathrm{i}}-\mathrm{f}_{\mathrm{i}}\right]$ are depicted in Table IX. The second module, for mixing materials and particulate process, is illustrated in Figure 19. The module is elicited from the HPM structure and it is mostly human-based. For automating or semi-automating those manual processes, the replacement rule set and other PRFS rule sets are activated so as to be converted to another developed functional structure according to the next step (Figure 20).

TABLE IX. SHARED $\left[\mathrm{f}_{\mathrm{i}}-\mathrm{F}_{\mathrm{i}}-\mathrm{f}_{\mathrm{i}}\right]$ AMONG SEVERAL MODULES.

\begin{tabular}{|c|c|c|c|}
\hline$\left[\mathbf{f}_{\mathbf{i}}-\mathbf{F}_{\mathbf{i}}-\mathbf{f}_{\mathbf{i}}\right]$ & Module-i & Module-i+1 & Occ $_{\mathbf{i}}$ \\
\hline Transfer ME & Grinding process & Particulate process & 1 \\
\hline Export particulate & Shared particulate process & Human intervention & 1 \\
\hline Convert HM to CS & Grinding process & Human intervention & 1 \\
\hline
\end{tabular}

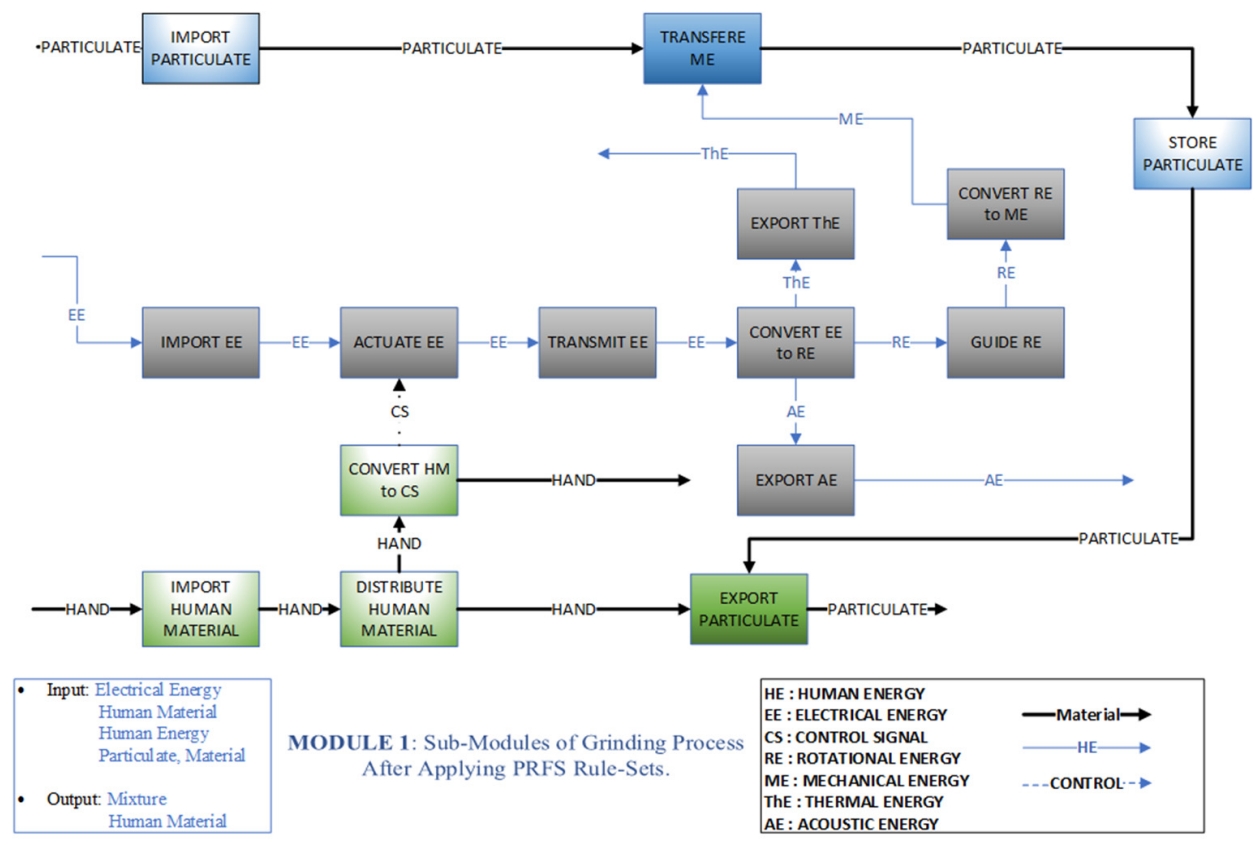

Fig. 18. Module-1 grinding process after applying PRFS rule sets.

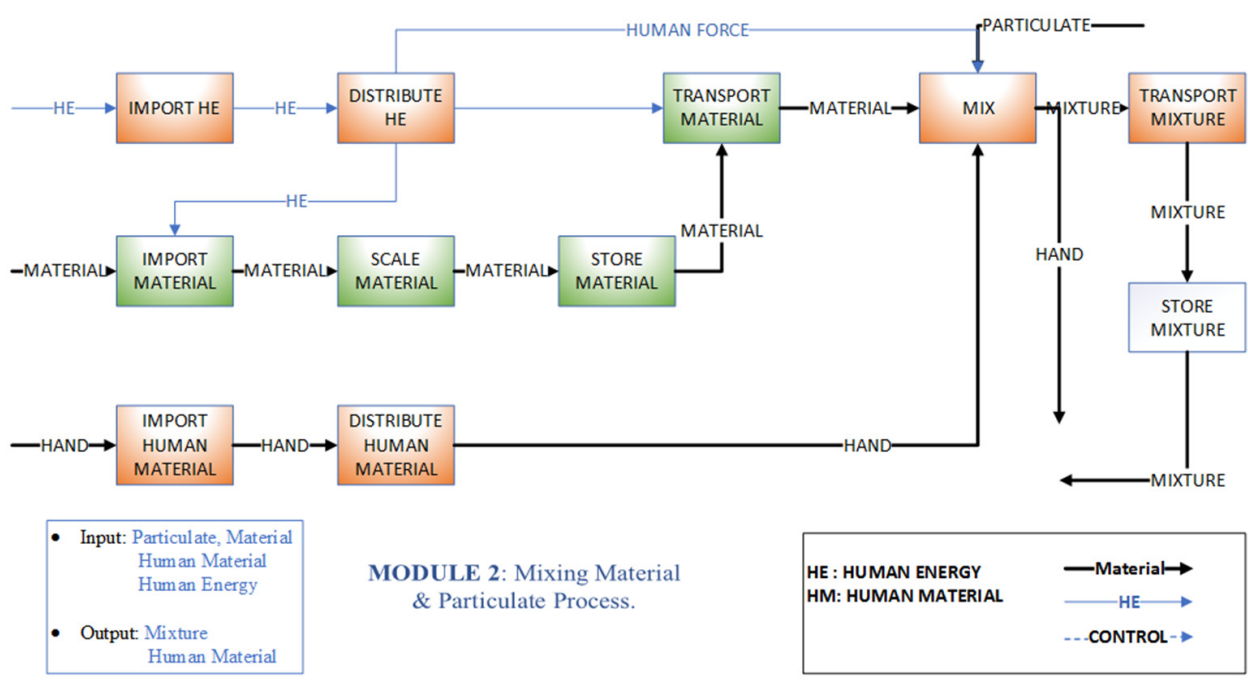

Fig. 19. Module-2 mixing material and particulate process. 


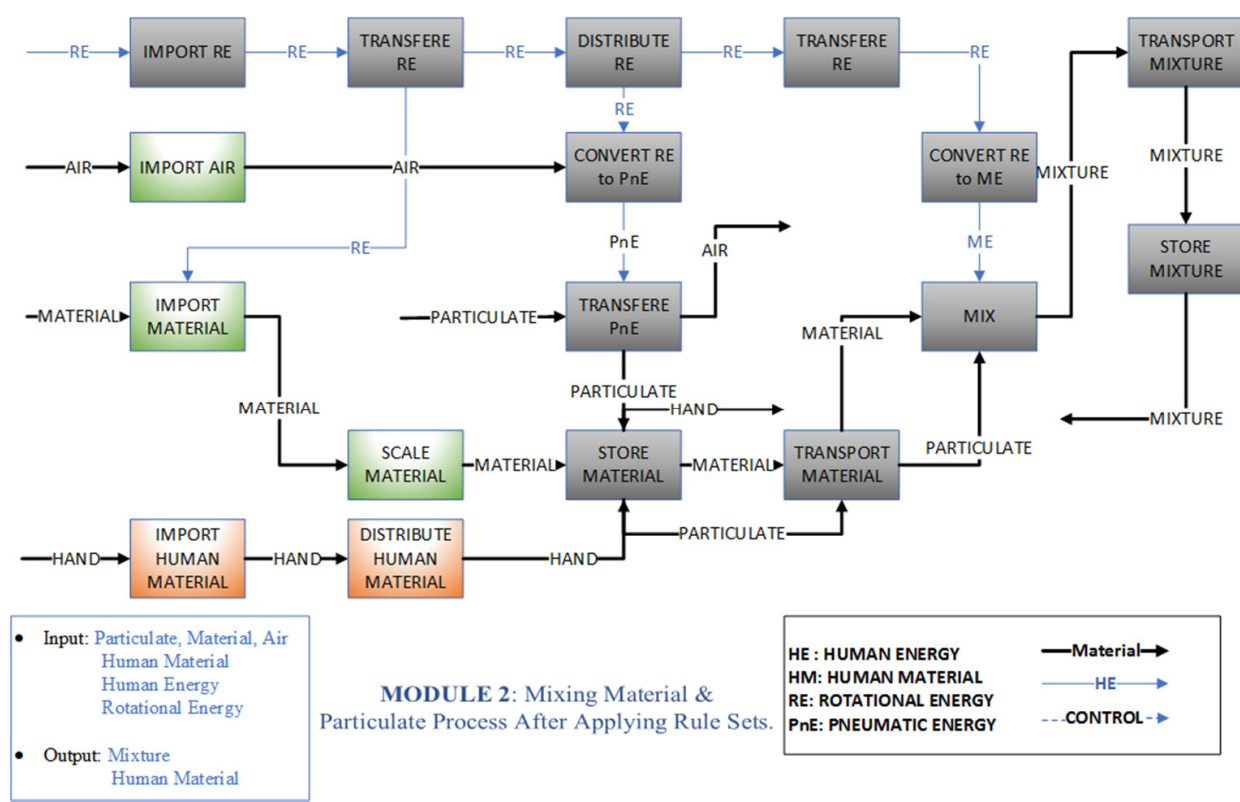

Fig. 20. Mixing material and particulate process after applying PRFS rule-sets.

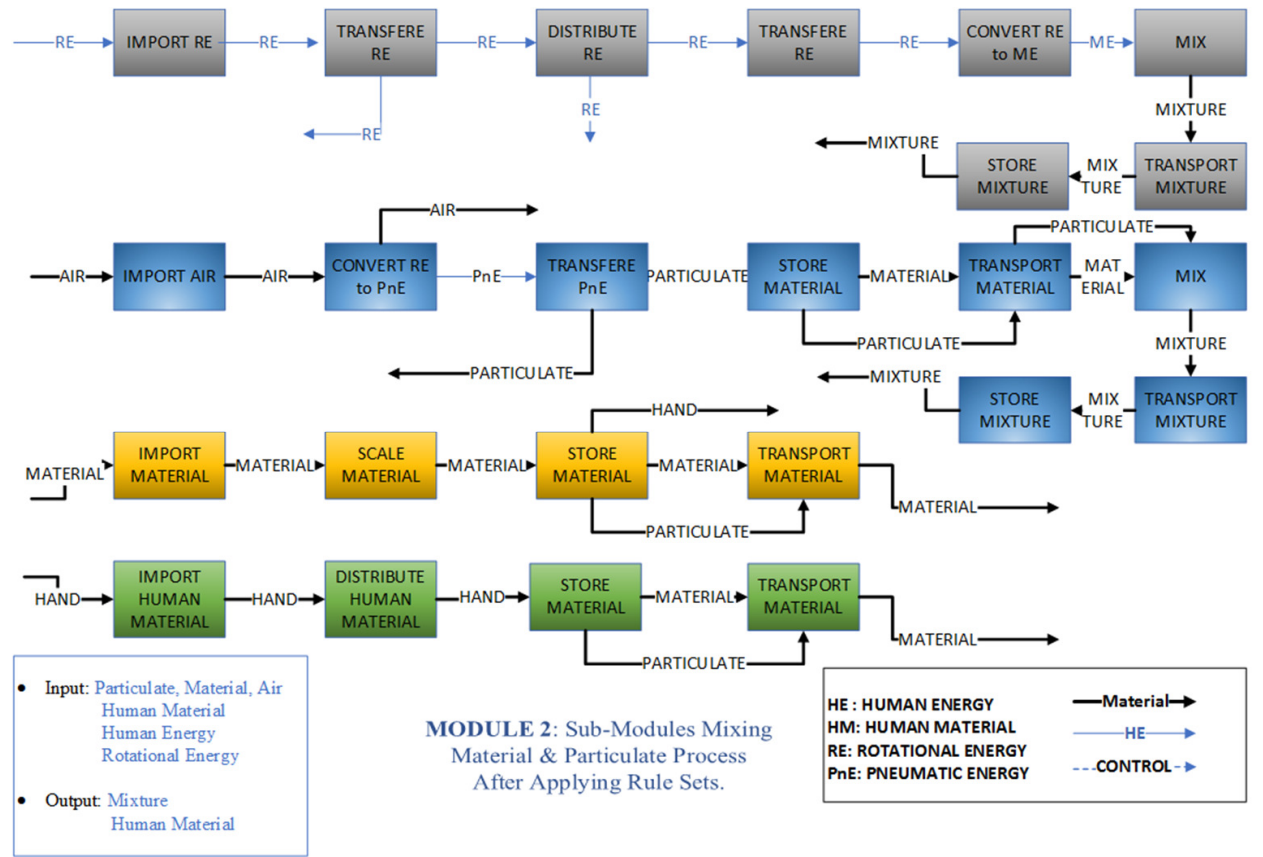

Fig. 21. Sub-modules of mixing material and particulate process after applying PRFS rule-sets.

\section{c) Aggregation}

Aggregation's core functionality is related with interactions through replacing human energy and materials with unknown sources of other kinds of energy and materials upon requirement. For instance, the first subfunction [HE-IMPORT$\mathrm{HE}]$ is changed after activating Rule-16 of replacement rule set in the PRFS algorithm and changed by [RE-IMPORT-RE], the subfunction [HE-TRANSPORT-HE] is changed after activating Rule-19 and produces [RE-TRANSPORT-RE], etc. (Figure 20). Module-2 is further decomposed into multiple submodules as depicted in Figure 21. Four sub-modules result from the HPM, where grey blocks refer to importing RE through the system to MIX function and storing Mixture, while the blue blocks refer to importing AIR through the system to transport grinded particulates, etc.

\section{d) Outline}

In Outline, the final module with the black box model and basic functional structure through comparing input/output flows is inspected. The complete functional structure of pharmaceutical grinder/mixer-blender is shown in Figure 22. 


\section{Summary of Case Study Functional Construction}

After applying the PRFS algorithm on the selected case study, the constructed functional structure model is decomposed into two main modules. Module-1 (Grinding Process and related operations) is further decomposed into three submodules, while Module-2 (mixing/blending materials and particulates and related operations) is further decomposed into four submodules, as illustrated in Table X. Generated submodules are the main input to concept generation.

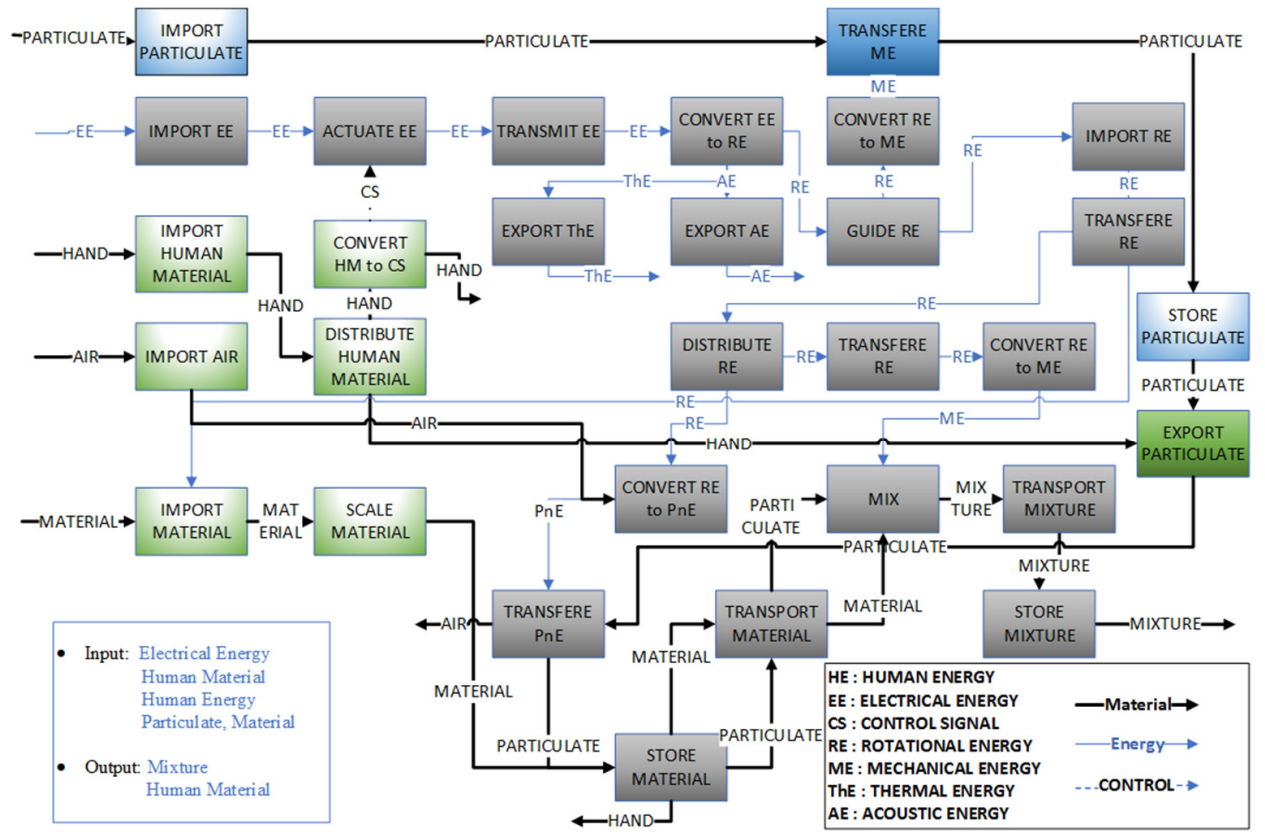

FS: Final Functional Structure FS of Pharmaceutical Grinder-Mixer/Blender

Fig. 22. Final complete FS of pharmaceutical grinder/mixer-blender.

TABLE $X . \quad$ SUMMARY OF CASE STUDY GENERATED MODULES AND THEIR DECOMPOSED SUB-MODULES

\begin{tabular}{|c|c|c|c|c|c|c|c|}
\hline M-i & \multicolumn{3}{|c|}{ Module-1 } & \multicolumn{4}{|c|}{ Module-2 } \\
\hline $\mathbf{S}_{\mathrm{i}} \mathbf{M}_{\mathbf{i}}$ & $\mathbf{S}_{1} \mathbf{M}_{1}$ & $\mathbf{S}_{2} \mathbf{M}_{2}$ & $\mathbf{S}_{3} \mathbf{M}_{1}$ & $\mathbf{S}_{1} \mathbf{M}_{2}$ & $\mathbf{S}_{2} \mathbf{M}_{2}$ & $\mathbf{S}_{3} \mathbf{M}_{2}$ & $\mathbf{S}_{4} \mathbf{M}_{2}$ \\
\hline 1 & $\begin{array}{c}\text { Import } \\
\text { EE }\end{array}$ & $\begin{array}{c}\text { Import } \\
\text { P. }\end{array}$ & $\begin{array}{c}\text { Import } \\
\text { HM }\end{array}$ & $\begin{array}{c}\text { Import } \\
\text { RE }\end{array}$ & $\begin{array}{l}\text { Import } \\
\text { M. }\end{array}$ & $\begin{array}{c}\text { Import } \\
\text { M. }\end{array}$ & $\begin{array}{c}\text { Import } \\
\mathrm{HM}\end{array}$ \\
\hline 2 & $\begin{array}{c}\text { Actuate } \\
\text { EE }\end{array}$ & $\begin{array}{c}\text { Transfer } \\
\text { ME }\end{array}$ & $\begin{array}{c}\text { Distribute } \\
\text { HM }\end{array}$ & $\begin{array}{c}\text { Transfer } \\
\text { RE }\end{array}$ & $\begin{array}{c}\text { Convert } \\
\text { RE to } \\
\text { PnE }\end{array}$ & $\begin{array}{c}\text { Process } \\
\text { M. }\end{array}$ & $\begin{array}{c}\text { Distribute } \\
\text { HM }\end{array}$ \\
\hline 3 & $\begin{array}{c}\text { Transmit } \\
\text { EE }\end{array}$ & Store P. & $\begin{array}{c}\text { Convert } \\
\text { HM to } \\
\text { CS }\end{array}$ & $\begin{array}{c}\text { Distribute } \\
\text { RE }\end{array}$ & $\begin{array}{c}\text { Transfer } \\
\text { PnE }\end{array}$ & Store M. & Store M. \\
\hline 4 & $\begin{array}{l}\text { Convert } \\
\text { EE to RE }\end{array}$ & $\begin{array}{c}\text { Export } \\
\text { P. }\end{array}$ & Export P. & $\begin{array}{c}\text { Convert } \\
\text { RE to } \\
\mathrm{ME}\end{array}$ & Store M. & $\begin{array}{c}\text { Transport } \\
\text { M. }\end{array}$ & $\begin{array}{c}\text { Transport } \\
\text { M. }\end{array}$ \\
\hline 5 & Guide RE & & & $\begin{array}{c}\text { Mix S.L. } \\
\text { to } \\
\text { Mixture }\end{array}$ & $\begin{array}{c}\text { Transport } \\
\text { M. }\end{array}$ & & \\
\hline 6 & $\begin{array}{c}\text { Convert } \\
\text { RE to ME }\end{array}$ & & & $\begin{array}{l}\text { Transport } \\
\text { Mixture }\end{array}$ & $\begin{array}{l}\text { Mix S.L. } \\
\text { to } \\
\text { Mixture }\end{array}$ & & \\
\hline 7 & $\begin{array}{c}\text { Transfer } \\
\text { ME }\end{array}$ & & & $\begin{array}{c}\text { Store } \\
\text { Mixture }\end{array}$ & $\begin{array}{c}\text { Transport } \\
\text { Mixture }\end{array}$ & & \\
\hline 8 & Store P. & & & & $\begin{array}{c}\text { Store } \\
\text { Mixture }\end{array}$ & & \\
\hline 9 & Export P. & & & & & & \\
\hline
\end{tabular}

\section{CONCLUSION AND FUTURE WORK}

After deliberated investigations, several aspects pertaining functional modeling structure have been revealed. The PRFS algorithm is an effective methodology for constructing functional structures procedurally according to restricted four rule-set groups. The PRFS algorithm has been proven for generality purposes, which is one of its main drawbacks in the existing literature. It can deal with many sources of databases and be integrated with other structured manual methods for concept generation such as QFD, TRIZ, etc.

Regarding future work, developing a searchable catalogue for categorized CRs with maximum level of generality and developing other catalogues for relating CR categories with selected flow types and categories within Reconciled Functional Basis, would be beneficial for completing the computerization cycle for all stages of the conceptual design phase.

\section{REFERENCES}

[1] G. Pahl, W. Beitz, J. Feldhusen, and K. H. Grote, Engineering Design: A Systematic Approach, 3rd ed. London, UK: Springer, 2007.

[2] L. D. Miles, Techniques of Value Analysis and Engineering. New York, NY, USA: McGraw-Hill, 1961.

[3] M. S. Hundal, "A Systematic method for developing function structures, solutions and concept variants," Mechanism and Machine Theory, vol. 25, no. 3, pp. 243-256, Jan. 1990, https://doi.org/10.1016/0094$114 \mathrm{X}(90) 90027-\mathrm{H}$

[4] K. T. Ulrich and S. D. Eppinger, Product Design and Development, 5th ed. New York, NY, USA: McGraw-Hill, 2011.

[5] K. Otto and K. Wood, Product Design: Techniques in Reverse Engineering and New Product Development, 1st ed. Upper Saddle River, NJ, USA: Pearson, 2000. 
[6] B. Hyman, Fundamentals of Engineering Design, 2nd ed. Upper Saddle River, NJ, USA: Pearson, 2002.

[7] D. Cutherell, "Product Architecture, in the PDMA," in The PDMA handbook of new product development, Chichester, UK: Wiley and Sons, 1996.

[8] W. G. Rodenacker and J. Schäfer, "Methodisches Konstruieren einer Anlage zur Herstellung von Atemkalk," Chemie Ingenieur Technik, vol. 50, no. 9, pp. 669-673, 1978, https://doi.org/10.1002/cite.330500905.

[9] H. Bassi and Y. A. Mobarak, "State-Space Modeling and Performance Analysis of Variable-Speed Wind Turbine Based on a Model Predictive Control Approach," Engineering, Technology \& Applied Science Research, vol. 7, no. 2, pp. 1436-1443, Apr. 2017, https://doi.org/ 10.48084/etasr. 1015 .

[10] K. Roth, Konstruieren mit Konstruktionskatalogen: Band 1: Konstruktionslehre, 3rd ed. Berlin Heidelberg, Germany: SpringerVerlag, 2000.

[11] R. Koller, Konstruktionslehre für den Maschinenbau: Grundlagen zur Neu- und Weiterentwicklung technischer Produkte mit Beispielen, 4th ed. Berlin Heidelberg, Germany: Springer-Verlag, 1998.

[12] K. Wood, "Functional analysis: A fundamental empirical study for reverse engineering, benchmarking and redesign," presented at the 1997 ASME DTM Conferenc, Jan. 1997.

[13] S. Sykman, R. D. Sriram, and J. Racz, "The Representation of Function in Computer-Based Design," in Proceedings of the 1999 ASME Design Engineering Technical Conferences (11th International Conference on Design Theory and Methodology), Las Vegas, NV, USA, Sep. 1999, Art. no. DETC99/DTM-8742.

[14] R. B. Stone and K. L. Wood, "Development of a Functional Basis for Design," Journal of Mechanical Design, vol. 122, no. 4, pp. 359-370, Aug. 1999, https://doi.org/10.1115/1.1289637.

[15] J. Hirtz, R. B. Stone, D. A. McAdams, S. Szykman, and K. L. Wood, "A functional basis for engineering design: Reconciling and evolving previous efforts," Research in Engineering Design, vol. 13, no. 2, pp. 65-82, Mar. 2002, https://doi.org/10.1007/s00163-001-0008-3.

[16] Y. Umeda, M. Ishii, M. Yoshioka, Y. Shimomura, and T. Tomiyama, "Supporting conceptual design based on the function-behavior-state modeler," AI EDAM, vol. 10, no. 4, pp. 275-288, Sep. 1996, https://doi.org/10.1017/S0890060400001621.

[17] Y. Shimomura, M. Yoshioka, H. Takeda, Y. Umeda, and T. Tomiyama, "Representation of Design Object Based on the Functional Evolution Process Model," Journal of Mechanical Design, vol. 120, no. 2, pp. 221-229, Jun. 1998, https://doi.org/10.1115/1.2826962.

[18] Y. Umeda, H. Takeda, T. Tomiyama, and H. Yoshikawa, "Function, behaviour, and structure," in Applications of Artificial Intelligence in Engineering V, vol. 1, J. S. Gero, Ed. Springer-Verlag, 1990, pp. 177 193.

[19] J. S. Gero and U. Kannengiesser, "The situated function-behaviourstructure framework," Design Studies, vol. 25, no. 4, pp. 373-391, Jul. 2004, https://doi.org/10.1016/j.destud.2003.10.010.

[20] W. Y. Zhang, S. B. Tor, G. A. Britton, and Y. M. Deng, "Functional design of mechanical products based on behavior-driven functionenvironment-structure modeling framework," Jan. 2002, Accessed: Dec. 25, 2020. [Online]. Available: https://dspace.mit.edu/handle/1721. $1 / 4031$.

[21] A. J. Robotham, "The use of function/means trees for modelling technical, semantic and business functions," Journal of Engineering Design, vol. 13, no. 3, pp. 243-251, Sep. 2002, https://doi.org/ $10.1080 / 09544820110108944$.

[22] V. H. Y. Lo, P. Humphreys, and D. Sculli, "The definition method zero applied toISO 9000 quality manuals," The TOM Magazine, vol. 13, no. 2, pp. 105-111, Jan. 2001, https://doi.org/10.1108/09544780110366060.

[23] R. L. Nagel, M. R. Bohm, R. B. Stone, and D. A. McAdams, "A representation of carrier flows for functional design," in Proceedings of ICED 2007, the 16th International Conference on Engineering Design, Paris, France, Jul. 2007, vol. DS42, pp. 413-414.

[24] R. B. Stone, R. Kurtadikar, N. Villanueva, and C. B. Arnold, "A customer needs motivated conceptual design methodology for product portfolio planning," Journal of Engineering Design, vol. 19, no. 6, pp. 489-514, Dec. 2008, https://doi.org/10.1080/09544820802286711.

[25] R. L. Nagel, R. B. Stone, R. Hutcheson, D. A. McAdams, and J. A. Donndelinger, "Function design framework (FDF): integrated process and function modeling for complex systems," in International Design Engineering Technical Conferences and Computers and Information in Engineering Conference, Jan. 2008, vol. 43284, pp. 273-286.

[26] R. L. Nagel, K. L. Perry, R. B. Stone, and D. A. McAdams, "FunctionCAD: A Functional Modeling Application Based on the Function Design Framework," in ASME 2009 International Design Engineering Technical Conferences and Computers and Information in Engineering Conference, Jul. 2010, pp. 591-600, https://doi.org/ 10.1115/DETC2009-87010.

[27] M. R. Bohm and R. B. Stone, "Form Follows Form: Fine Tuning Artificial Intelligence Methods," in ASME 2010 International Design Engineering Technical Conferences and Computers and Information in Engineering Conference, Mar. 2011, pp. 519-528, https://doi.org/ 10.1115/DETC2010-28774.

[28] M. R. Bohm, R. B. Stone, and R. L. Nagel, "Form Follows Form: Is a New Paradigm Needed?," in ASME 2009 International Mechanical Engineering Congress and Exposition, Jul. 2010, pp. 165-175, https://doi.org/10.1115/IMECE2009-10410.

[29] J. Pailhès, M. Sallaou, J.-P. Nadeau, and G. M. Fadel, "Energy Based Functional Decomposition in Preliminary Design," Journal of Mechanical Design, vol. 133, no. 051011, Jun. 2011, https://doi.org/ 10.1115/1.4004193.

[30] J. C. Wu, K. Poppa, M. C. Leu, and X. F. Liu, "Integrated function structure and object-oriented design framework," Computers in Industry, vol. 63, no. 5, pp. 458-470, Jun. 2012, https://doi.org/10.1016/ j.compind.2012.01.011.

[31] C. Sen, J. D. Summers, and G. M. Mocko, "A Formal Representation of Function Structure Graphs for Physics-Based Reasoning," Journal of Computing and Information Science in Engineering, vol. 13, no. 021001, Apr. 2013, https://doi.org/10.1115/1.4023167.

[32] C. Sen and J. D. Summers, "A Pilot Protocol Study on How Designers Construct Function Structures in Novel Design," in Design Computing and Cognition '12, Dordrecht, 2014, pp. 247-264, https://doi.org/ 10.1007/978-94-017-9112-0_14.

[33] R. L. Nagel, M. R. Bohm, J. S. Linsey, and M. K. Riggs, "Improving Students' Functional Modeling Skills: A Modeling Approach and a Scoring Rubric," Journal of Mechanical Design, vol. 137, no. 051102 , May 2015, https://doi.org/10.1115/1.4029585.

[34] J. Ma, J. Hu, J.-F. Feng, J. Qi, and Y.-H. Peng, "Constrained FBS knowledge cell model, representation, and applications for conceptual design," Proceedings of the Institution of Mechanical Engineers, Part C: Journal of Mechanical Engineering Science, vol. 230, no. 11, pp. 17731786, Jun. 2016, https://doi.org/10.1177/0954406215585366.

[35] L. Fiorineschi, F. Rotini, and P. Rissone, "A new conceptual design approach for overcoming the flaws of functional decomposition and morphology," Journal of Engineering Design, vol. 27, no. 7, pp. 438468, Jul. 2016, https://doi.org/10.1080/09544828.2016.1160275.

[36] A. Patel, W. Kramer, J. D. Summers, and M. Shuffler-Porter, "Function Modeling: A Study of Sequential Model Completion Based on Count and Chaining of Functions," in ASME 2016 International Design Engineering Technical Conferences and Computers and Information in Engineering Conference, Dec. 2016, https://doi.org/10.1115/ DETC2016-59860.

[37] A. S. Gill, J. D. Summers, and C. J. Turner, "Impact of Level of Detail and Information Content on Accuracy of Function Structure-Based Market Price Prediction Models," presented at the ASME 2016 International Design Engineering Technical Conferences and Computers and Information in Engineering Conference, Dec. 2016, https://doi.org/ 10.1115/DETC2016-59662.

[38] J. Wan, A. Canedo, and M. A. A. Faruque, "Functional Model-Based Design Methodology for Automotive Cyber-Physical Systems," IEEE Systems Journal, vol. 11, no. 4, pp. 2028-2039, Dec. 2017, https://doi.org/10.1109/JSYST.2014.2387487.

[39] C. Lu, H. Chai, M. Tian, X. Peng, and S. Jiang, "Product function combination design based on functional redundancy analysis," 
Concurrent Engineering, vol. 25, no. 3, pp. 229-244, Sep. 2017, https://doi.org/10.1177/1063293X17705180.

[40] A. Patel, W. S. Kramer, M. Flynn, J. D. Summers, and M. L. Shuffler, "Function Modeling: An Analysis of Pause Patterns in Modeling Activities," in ASME 2018 International Design Engineering Technical Conferences and Computers and Information in Engineering Conference, Nov. 2018, https://doi.org/10.1115/DETC2018-86103.

[41] A. S. Gill, J. D. Summers, and C. Sen, "Impact of Chaining Method and Level of Completion on Accuracy of Function Structure-Based Market Price Prediction Models," Journal of Computing and Information Science in Engineering, vol. 19, no. 4, Aug. 2019, Art. no. 041018, https://doi.org/10.1115/1.4043210.

[42] O. M. Mohammed and A. Z. Shammari, "Function Modeling in Engineering Design: Approaches and Methods," Technium: Romanian Journal of Applied Sciences and Technology, vol. 2, no. 7, pp. 222-239, 2020, https://doi.org/10.47577/technium.v222i2.1790.

[43] A. R. Patel, "An Investigation of Modeling Behaviors in Function Structure Modeling With Respect to Chaining Methods," M.S. thesis, Clemson University, Clemson, SC, USA, 2018. 